\title{
The effect of nifedipine on retinal venous pressure of glaucoma patients with the Flammer-Syndrome
}

\author{
L. Fang $^{1} \cdot$ S. Turtschi $^{1} \cdot$ Maneli Mozaffarieh ${ }^{1}$
}

Received: 6 December 2014 /Revised: 17 March 2015 / Accepted: 25 March 2015 /Published online: 12 April 2015

(C) Springer-Verlag Berlin Heidelberg 2015

\begin{abstract}
Purpose The purpose was to measure the retinal venous pressure (RVP) in both eyes of primary open-angle glaucoma (POAG) patients before and 3 weeks after treatment with low-dosed Nifedipine.

Methods This retrospective study included 20 POAG patients who were treated with Nifedipine (5 mg daily) and 20 untreated control POAG patients. In both the treated and untreated control group, a distinction was made between those patients who had the Flammer-Syndrome (FS) and those who did not. The RVP was measured in all patients bilaterally at baseline and 3 weeks later by means of contact lens ophthalmodynamometry and the RVP measurements of the treated POAG patients were compared to the RVPs of the untreated POAG controls. Ophthalmodynamometry is done by applying an increasing force on the eye via a contact lens. The minimum force required to induce a venous pulsation is called the ophthalmodynamometric force (ODF). The RVP is defined and calculated as the sum of ODF and intraocular pressure (IOP) $[\mathrm{RVP}=\mathrm{ODF}+\mathrm{IOP}]$.

Results The RVP decreased significantly after 3 weeks in both eyes of patients treated with low-dosed Nifedipine compared to the untreated group (mean decrease of $12.5 \mathrm{mmHg}$ (SD 12.5), $P<0.001)$. A larger response to therapy was found in patients with the FS compared to patients lacking the FS (mean decrease of 16.07 vs. $7.28 \mathrm{mmHg}$, confidence Interval (CI): 5.2 to 9.3 vs. 12.3 to $19.7 ; P<0.001$ ). No significant differences were accounted for in the IOP's of the patients after treatment. In the untreated control group, no significant differences were accounted for either in the RVP or the IOP after 3 weeks.
\end{abstract}

Maneli Mozaffarieh

Maneli.Mozaffarieh@usb.ch

1 Department of Ophthalmology, University of Basel, Mittlere Strasse 91, 4031 Basel, Switzerland
Conclusions Treatment with low-dosed Nifedipine decreases RVP in both eyes of glaucoma patients, particularly in those with the Flammer-Syndrome. This effect may be due to the partial inhibition of Endothelin-1 (ET-1) by Nifedipine.

Keywords Retinal venous pressure · Flammer-Syndrome . Nifedipine

\section{Introduction}

Calcium channel blockers (CCBs) such as Nifedipine are a chemically and pharmacologically diverse group of drugs that reduce the calcium conduction of calcium channels. The selectivity of CCBs for the heart and smooth muscle cells varies $[1,2]$. Nifedipine belongs chemically to the group of dihydropyridines, which in contrast to other $\mathrm{CCBs}$, have a greater selectivity for vascular smooth muscle [3] than for myocardium because they block smooth muscle calcium channels at concentrations below those required for significant cardiac effects. In smooth muscle cells, intracellular calcium concentration is partly regulated by ET-1 [4].

Under physiological conditions, the majority of ET-1 is produced by the vascular endothelial cells. The ET-1 is secreted predominantly abluminally, but a small portion is secreted intraluminally, thereby leading to a certain concentration of ET-1 in the blood [5, 6]. Increased levels of ET-1 have been reported in glaucoma patients, particularly in those with a primary vascular dysregulation [7-11]. The ET-1 plays a role in the pathogenesis of glaucomatous damage by constricting extraocular vessels $[12,13]$, reducing optic nerve head blood flow [14], impairing anterograde and retrograde axoplasmatic transport [15, 16] and activating astrocytes [17]. Being a vasoconstrictor, it may also plays an important role in constricting the retinal veins locally [18] thereby leading to an increased retinal venous pressure (RVP) as observed in glaucoma patients [19-23]. 
Since ET-1 is involved in the pathogenesis of glaucomatous damage, the therapeutic use of ET-1 blockers are of interest. Although ET-1 blockers are used for experimental work, they are not yet clinically available for use in glaucoma. We know, however, that CCBs, such as Nifedipine, inhibit contractions to ET-1 in the porcine ciliary arteries, while endotheliumdependent relaxation to bradykinin as well as endotheliumindependent relaxation to $\mathrm{Na}+$ nitroprusside remains unaffected [24]. By acting on vascular smooth muscle, Nifedipine can lead to vasodilation or relief from vasospasm $[25,26]$, and can partially block the effect of ET-1 [27]. Recently, it was shown that glaucoma patients, particularly those with the FlammerSyndrome (FS) [28], had significantly higher RVPs [29]. To see whether treatment with Nifedipine affects ocular hemodynamics we retrospectively analysed RVPs of eyes of glaucoma patients (with and without FS) who were treated with Nifedipine and compared results to an untreated control group (with and without FS).

\section{Methods}

\section{Patients}

We retrospectively analysed values of RVP and IOP of 40 POAG patients, 20 of which were treated systemically only with Nifedipine ( $5 \mathrm{mg}$ daily) and 20 of which who had no systemic treatment. No ethical approval was required to measure RVP in glaucoma patients as RVP measurements are always taken in all glaucoma patients at the Department of Ophthalmology of the University of Basel. All patients had glaucomatous visual fields or glaucomatous optic nerve cupping and the absence of alternative causes of optic neuropathy.

\section{The Flammer-Syndrome}

A distinction was made between those patients who had the FS and those who did not. The FS was defined as being present if it was detected in the patient history and confirmed by the dynamic retinal vessel analyser (DVA). Cases in which the patient history and DVA results were contradictory were excluded from the study.
Evaluation of patient history for FS: FS is defined as present (FS+) in the patient history if the subjects answer five of the following six questions with "Yes", and it is defined as absent (FS-) if the subjects answer less than five questions with "Yes": 1) Do you suffer from cold hands or feet even in summer [30]?; 2) Do you have trouble falling asleep, especially when you are cold [31]?; 3) Are you seldom thirsty, and do you have to remind yourself to drink enough [32]?; 4) Do you suffer from migraine attacks [33]?; 5) Do you have low blood pressure [34]?; and 6) Do you identify smells better than others [35]?

Evaluation of DVA results for FS was that the results of DVA were considered positive for FS (pathological) if the reaction of the vessels in both eyes was reduced in response to flickering light.

\section{Application of nifedipine}

Nifedipine was applied orally in the form of liquid drops (Nifedipine Ratiopharm Drops, 1 drop=1 mg Nifedipine) mixed in 11 of water and the patients were told to drink the 11 of liquid slowly throughout the day. The reason for this particular application was due to the fact that Nifedipine has a short halflife (approximately $15 \mathrm{~min}$ ) and its systemic effect can be increased when taken in this manner.

\section{Measurement of RVP}

For all patients RVP was measured in both eyes by ophthalmodynamometry (IMEDOS Jena Germany) at baseline and 3 weeks later. This device consists of a conventional Goldmann contact lens fitted with a pressure sensor at its outer margin where the Goldmann contact lens is usually held during an ophthalmoscopic examination. The contact lens is fitted to an outer ring by strain gauges, which give an electrical signal. This signal is linearly related to the force by which the contact lens is attached to the eye. It is given to the input of a central unit by a thin flexible cable. This central unit has the size of a pocket calculator. It shows the increase of the IOP induced by the force applied on a LCD display. The conversion from force to pressure is based on a biophysical calibration [36, 37].

Ophthalmodynamometry was conducted by applying increasing force to the eye via the contact lens. This applied pressure can be read as a pressure increase on the attached
Table 1 Demographic and baseline characteristics of the two groups of patients

\begin{tabular}{llll}
\hline & POAG Treated with Nifedipine & Control POAG & P-Value \\
\hline N (FS+/FS-) & $20(11 / 9)$ & $20(7 / 13)$ & \\
Gender (F/M) & $(10 / 10)$ & $(12 / 10)$ & n.s \\
Age Mean (SD) & $56.7(14.9)$ & $60.6(16.3)$ & n.s \\
\hline
\end{tabular}

$F S+$ patients with the Flammer-Syndrome

$F S$ - patients who did not have the Flammer-Syndrome 
Fig. 1 Intraocular pressure (IOP) and retinal venous pressure (RVP) in the group of patients treated with Nifedipine. Measurements were taken at baseline and after 3 weeks



LCD screen based on a calibration curve. Any small pulsatile synchronous movement of the central retinal vein or its major branches inside the optic disc was noted as spontaneous pulsation. In short, after placing the contact lens on the eye, the ONH was brought into sight. If a spontaneous venous pulsation was present it was noted. If not, the compressive force was increased until the first venous pulsation was detected, and the measurement value was fixed and read. RVP was calculated as the sum of pressure increase induced by the instrument and IOP as measured by Goldman tonometry. Measurements by the ophthalmodynamometer are reproducible [29].

\section{Statistical analysis}

Descriptive statistics are presented as mean (SD). Overall, pvalues were calculated using ANOVA based on linear mixed effects models (with the exception of patient's age).

To compare the RVP change from baseline between the group with Nifedipine therapy and the control group, a linear mixed-effects model was performed. Mixed effects models are suitable tools to examine repeated measure data.

The dependent variable is the RVP change from baseline, the independent variables are "study group," "FS" (FlammerSyndrome), "age", "baseline RVP," and "eye-side." Hence, results are adjusted for "age," "baseline RVP," and "eyeside." Subjects are treated as random factor. A potential interaction between "FS" and "Group" is also included in the regression model.

Results are presented as differences of the means of the two groups, namely treated and untreated control, with corresponding $95 \%$ confidence interval and p-value. A p-value $<0.05$ is considered significant. All analyses were conducted using the statistical software package R, version 3.1.1. Mixed effects models are performed using the package "nlme."

\section{Results}

Table 1 gives an overview of the demographic data of patients and controls. RVP decreased significantly after 3 weeks in
Fig. 2 Intraocular pressure (IOP) and retinal venous pressure (RVP) in the control group (no treatment). Measurements were taken at baseline and after 3 weeks




both eyes of patients treated with low-dosed Nifedipine compared to the untreated group (mean decrease of $12.5 \mathrm{mmHg}$ (SD 12.5), $P<0.001$ ). A larger response to therapy was found in patients with the FS compared to patients lacking the FS (mean decrease of $16.07 \mathrm{mmHg}$ vs. $7.28 \mathrm{mmHg}$, Confidence Interval (CI): 5.2 to 9.3 vs. 12.3 to $19.7 ; P<0.001$ ). No significant differences were accounted for in the IOP's of the patients after treatment (Fig. 1). In the untreated control group, no significant differences were accounted for either in the RVP or the IOP after 3 weeks (Fig. 2).

\section{Discussion}

An increased RVP in the eyes of glaucoma patients has previously been reported [19-23], and in a previous study we observed that this increase is higher in patients with the Flammer-Syndrome [38]. To the best of our knowledge, this is the first report showing the possibility of a therapeutic reduction of RVP by the low-dosed calcium channel blocker Nifedipine.

At present, the cause of this increased RVP and the fact that it can be therapeutically reduced by means of low-dosed $\mathrm{Ni}$ fedipine is not known. At the moment we can only hypothesize that the increased RVP may possibly in part be due to a dysregulation of the veins [18]. This may explain why we can reduce it by means of the $\mathrm{CCB}$, Nifedipine. Both retinal arteries and veins, like elsewhere in the body, are highly regulated. In general, however, the regulation of the arteries has attracted more attention. In patients with a dysregulation the arteries produce an increased amount of ET-1 [39]. This increases both the ET-1 concentration in the circulating blood [40] as well as the ET- 1 concentration in the surrounding tissue of the artery causing nearby veins to react with a vasoconstriction [18].

Supportive of this hypothesis are the various studies showing the effect of $\mathrm{CCB}$ on ocular blood flow. Ex vivo studies show that CCBs reduce the vasoconstrictive effect of ET-1 $[24,41]$. Various animal studies show that OBF, particularly ONH blood flow [42], is increased after application of CCBs, such as nicardipine [43, 44]. CCBs mitigate the OBF-reducing effect of an ET-1 infusion in healthy volunteers [27]. Studies on healthy subjects with PVD show that CCBs improve the regulation of blood flow [45]. Finally, studies on glaucoma patients also show an improvement in $\mathrm{OBF}[38,46,47]$.

This study has limitations, as it is retrospective and not randomized. Future randomized, controlled studies are warranted to clarify the effect of CCBs on the increased RVP of glaucoma patients with the Flammer-Syndrome.

Conflict of Interest Statement All authors certify that they have no affiliations with or involvement in any organization or entity with any financial interest (such as honoraria, educational grants, participation in speakers' bureaus, membership, employment, consultancies, stock ownership, or other equity interest, expert testimony, or patent-licensing arrangements), or non-financial interest (such as personal or professional relationships, affiliations, knowledge, or beliefs) in the subject matter or materials discussed in this manuscript.

\section{References}

1. Noll G, Luscher TF (1998) Comparative pharmacological properties among calcium channel blockers: T-channel versus L-channel blockade. Cardiology 89(Suppl 1):10-15

2. Magnon M, Gallix P, Cavero I (1995) Intervessel (arteries and veins) and heart/vessel selectivities of therapeutically used calcium entry blockers: variable, vessel-dependent indexes. J Pharmacol Exp Ther 275(3):1157-1166

3. Sung JY, Choi HC (2012) Nifedipine inhibits vascular smooth muscle cell proliferation and reactive oxygen species production through AMP-activated protein kinase signaling pathway. Vasc Pharmacol 56(1-2):1-8. doi:10.1016/j.vph.2011.06.001

4. Wynne BM, Chiao CW, Webb RC (2009) Vascular smooth muscle cell signaling mechanisms for contraction to angiotensin II and endothelin-1. J Am Soc Hypertens JASH 3(2):84-95. doi:10. 1016/j.jash.2008.09.002

5. Flammer J, Mozaffarieh M (2013) Basic sciences in ophthalmology physics and chemistry. Springer, Berlin

6. Maneli M, Josef F (2009) Ocular blood flow and glaucomatous optic neuropathy. Springer, Berlin

7. Emre M, Orgul S, Haufschild T, Shaw SG, Flammer J (2005) Increased plasma endothelin-1 levels in patients with progressive open angle glaucoma. Br J Ophthalmol 89(1):60-63. doi:10.1136/ bjo.2004.046755

8. Gass A, Flammer J, Linder L, Romerio SC, Gasser P, Haefeli WE (1997) Inverse correlation between endothelin-1-induced peripheral microvascular vasoconstriction and blood pressure in glaucoma patients. Graefe's archive for clinical and experimental ophthalmology. Graefes Arch Clin Exp Ophthalmol 235(10):634-638

9. Lee NY, Park HY, Na KS, Park SH, Park CK (2013) Association between heart rate variability and systemic endothelin-1 concentration in normal-tension glaucoma. Curr Eye Res 38(4):516-519. doi: 10.3109/02713683.2012.745881

10. Choritz L, Machert M, Thieme H (2012) Correlation of endothelin1 concentration in aqueous humor with intraocular pressure in primary open angle and pseudoexfoliation glaucoma. Invest Ophthalmol Vis Sci 53(11):7336-7342. doi:10.1167/iovs. 1210216

11. Flammer J, Konieczka K, Flammer AJ (2013) The primary vascular dysregulation syndrome: implications for eye diseases. EPMA J 4(1):14. doi:10.1186/1878-5085-4-14

12. Haefliger IO, Flammer J, Luscher TF (1992) Nitric oxide and endothelin-1 are important regulators of human ophthalmic artery. Invest Ophthalmol Vis Sci 33(7):2340-2343

13. Meyer P, Flammer J, Luscher TF (1993) Endothelium-dependent regulation of the ophthalmic microcirculation in the perfused porcine eye: role of nitric oxide and endothelins. Invest Ophthalmol Vis Sci 34(13):3614-3621

14. Schmetterer L, Findl O, Strenn K, Jilma B, Graselli U, Eichler HG, Wolzt M (1997) Effects of endothelin-1 (ET-1) on ocular hemodynamics. Curr Eye Res 16(7):687-692

15. Stokely ME, Yorio T, King MA (2005) Endothelin-1 modulates anterograde fast axonal transport in the central nervous system. J Neurosci Res 79(5):598-607. doi:10.1002/jnr.20383 
16. Taniguchi T, Shimazawa M, Sasaoka M, Shimazaki A, Hara H (2006) Endothelin-1 impairs retrograde axonal transport and leads to axonal injury in rat optic nerve. Curr Neurovasc Res 3(2):81-88

17. Prasanna G, Krishnamoorthy R, Clark AF, Wordinger RJ, Yorio $\mathrm{T}$ (2002) Human optic nerve head astrocytes as a target for endothelin-1.INVEST. OPHTH VIS SCI 43(8):2704-2713

18. Fraenkl SA, Mozaffarieh M, Flammer J (2010) Retinal vein occlusions: the potential impact of a dysregulation of the retinal veins. EPMA J 1(2):253-261. doi:10.1007/s13167-010-0025-2

19. Jonas JB (2003) Central retinal artery and vein collapse pressure in eyes with chronic open angle glaucoma. Br J Ophthalmol 87(8): 949-951

20. Morgan WH, Balaratnasingam C, Hazelton ML, House PH, Cringle SJ, Yu DY (2005) The force required to induce hemivein pulsation is associated with the site of maximum field loss in glaucoma. Invest Ophthalmol Vis Sci 46(4):1307-1312. doi:10.1167/ iovs. 04-1126

21. Morgan WH, Hazelton ML, Balaratnasingamm C, Chan H, House PH, Barry CJ, Cringle SJ, Yu DY (2009) The association between retinal vein ophthalmodynamometric force change and optic disc excavation. Br J Ophthalmol 93(5):594-596. doi:10.1136/bjo. 2008.149963

22. Stodtmeister R (2008) The pulsation and the pressure of the central retinal vein and their relation to glaucoma damage and therapy. Klin Monbl Augenheilkd 225(7):632-636. doi:10.1055/s-20081027233

23. Stodtmeister R, Ventzke S, Spoerl E et al (2013) Enhanced pressure in the central retinal vein decreases the perfusion pressure in the prelaminar region of the optic nerve head. Invest Ophthalmol Vis Sci 54:4698-4704

24. Meyer P, Lang MG, Flammer J, Luscher TF (1995) Effects of calcium channel blockers on the response to endothelin-1, bradykinin and sodium nitroprusside in porcine ciliary arteries. Exp Eye Res 60(5):505-510

25. Gasser P, Flammer J (1990) Short- and long-term effect of nifedipine on the visual field in patients with presumed vasospasm. J Int Med Res 18(4):334-339

26. Guthauser U, Flammer J, Niesel P (1987) The relationship between the visual field and the optic nerve head in glaucomas. Graefe's archive for clinical and experimental ophthalmology. Graefes Arch Clin Exp Ophthalmol 225(2):129-132

27. Strenn K, Matulla B, Wolzt M, Findl O, Bekes MC, Lamsfuss U, Graselli U, Rainer G, Menapace R, Eichler HG, Schmetterer L (1998) Reversal of endothelin-1-induced ocular hemodynamic effects by low-dose nifedipine in humans. Clin Pharmacol Ther 63(1):54-63. doi:10.1016/S0009-9236(98)90121-7

28. Konieczka K, Ritch R, Traverso CE, Kim DM, Kook MS, Gallino A, Golubnitschaja O, Erb C, Reitsamer HA, Kida T, Kurysheva N, Yao K (2014) Flammer syndrome. EPMA J 5(1):11. doi:10.1186/ 1878-5085-5-11

29. Fang L, Baertschi M, Mozaffarieh M (2014) The effect of flammersyndrome on retinal venous pressure. BMC Ophthalmol 14:121. doi:10.1186/1471-2415-14-121

30. Mozaffarieh M, Fontana Gasio P, Schotzau A, Orgul S, Flammer J, Krauchi K (2010) Thermal discomfort with cold extremities in relation to age, gender, and body mass index in a random sample of a Swiss urban population. Popul Health Metr 8:17. doi:10.1186/ 1478-7954-8-17

31. Pache M, Krauchi K, Cajochen C, Wirz-Justice A, Dubler B, Flammer J, Kaiser HJ (2001) Cold feet and prolonged sleep-onset latency in vasospastic syndrome. Lancet 358(9276):125-126. doi: 10.1016/S0140-6736(01)05344-2
32. Teuchner B, Orgul S, Ulmer H, Haufschild T, Flammer J (2004) Reduced thirst in patients with a vasospastic syndrome. Acta Ophthalmol Scand 82(6):738-740. doi:10.1111/j.1600-0420.2004. 00376.x

33. Gasser P, Meienberg O (1991) Finger microcirculation in classical migraine. A video-microscopic study of nailfold capillaries. Eur J Neurol 31(3):168-171

34. Orgul S, Kaiser HJ, Flammer J, Gasser P (1995) Systemic blood pressure and capillary blood-cell velocity in glaucoma patients: a preliminary study. Eur J Ophthalmol 5(2):88-91

35. Mozaffarieh M, Hauenstein D, Schoetzau A, Konieczka K, Flammer J (2010) Smell perception in normal tension glaucoma patients. Mol Vis 16:506-510

36. Löw UG (2002) Kalibrierung des Kontaktglasdynamometers an enukleierten Schweineaugen und klinischer Vergleich zwischen dem Kontaktglasdynamometer und der Smartlens. Medizinische Fakultaet der Universitaet des Saarlandes. Ref Type: Thesis/ Dissertation

37. Morgan WH, Cringle SJ, Kang MH et al (2010) Optimizing the calibration and interpretation of dynamic ocular force measurements. Graefes Arch Clin Exp Ophthalmol 248:401-407

38. Geyer O, Neudorfer M, Kessler A, Firsteter E, Lazar M, Almog Y (1996) Effect of oral nifedipine on ocular blood flow in patients with low tension glaucoma. Br J Ophthalmol 80(12):1060-1062

39. Haufschild T, Prunte C, Messerli J, Flammer J (2004) Increased endothelin-1 plasma level in young adults with retinal vascular occlusive diseases. Klin Monbl Augenheilkd 221(5):357-359. doi:10.1055/s-2004-812813

40. Lee NY, Park HY, Park CK, Ahn MD (2012) Analysis of systemic endothelin-1, matrix metalloproteinase-9, macrophage chemoattractant protein-1, and high-sensitivity C-reactive protein in normal-tension glaucoma. Curr Eye Res 37(12):1121-1126. doi: $10.3109 / 02713683.2012 .725798$

41. Lang MG, Zhu P, Meyer P, Noll G, Haefliger IO, Flammer J, Luscher TF (1997) Amlodipine and benazeprilat differently affect the responses to endothelin- 1 and bradykinin in porcine ciliary arteries: effects of a low and high dose combination. Curr Eye Res 16(3):208-213

42. Toriu N, Sasaoka M, Shimazawa M, Sugiyama T, Hara H (2001) Effects of lomerizine, a novel Ca2 + channel blocker, on the normal and endothelin-1-disturbed circulation in the optic nerve head of rabbits. J Ocul Pharmacol Ther 17(2):131-149. doi:10.1089/ 10807680151125456

43. Noguchi S, Kimura Y, Nitta A, Shimizu R, Kobayashi K, Aoki K, Maruyama Y, Isono H, Shimizu M (1992) Blood flow in the optic nervehead following intravenous administration of calcium antagonist. Nihon Ganka Gakkai Zasshi 96(8):967-972

44. Tamaki Y, Araie M, Tomita K, Tomidokoro A (1996) Time-course of changes in nicardipine effects on microcirculation in retina and optic nerve head in living rabbit eyes. Jpn J Ophthalmol 40(2):202211

45. Gasser P, Flammer J, Mahler F (1988) The use of calcium antagonists in the treatment of ocular circulation symptoms in the framework of a vasospastic syndrome. Swiss Med Wkly 118(6):201-202

46. Koseki N, Araie M, Tomidokoro A, Nagahara M, Hasegawa T, Tamaki Y, Yamamoto S (2008) A placebo-controlled 3-year study of a calcium blocker on visual field and ocular circulation in glaucoma with low-normal pressure. Ophthalmology 115(11):2049 2057. doi:10.1016/j.ophtha.2008.05.015

47. Tomita G, Niwa Y, Shinohara H, Hayashi N, Yamamoto T, Kitazawa Y (1999) Changes in optic nerve head blood flow and retrobular hemodynamics following calcium-channel blocker treatment of normal-tension glaucoma. Int Ophthalmol 23(1):3-10 